\title{
The Significance of Cognitive Phenomenology
}

\begin{abstract}
This is the second in a series of two articles that serve as an introduction to recent debates about cognitive phenomenology. Cognitive phenomenology can be defined as the experience that is associated with cognitive activities, such as thinking, reasoning, and understanding. What is at issue in contemporary debates is not the existence of cognitive phenomenology, so defined, but rather its nature and theoretical role. The first article examines questions about the nature of cognitive phenomenology, while the second article explores the philosophical implications of these questions for the role of consciousness in theories of intentionality, introspective self-knowledge, and knowledge of the external world.
\end{abstract}

\section{Introduction}

The previous article examined the following pair of questions about the nature of cognitive phenomenology:

(1) The Intentionality Question. What is the relationship between the phenomenology of cognition and the intentionality of cognition? Are the phenomenal properties of cognition identical with or distinct from intentional properties of cognition? 
(2) The Reduction Question. What is the relationship between the phenomenology of cognition and the phenomenology of sensory perception? Are the phenomenal properties of cognition identical with or distinct from phenomenal properties of sensory perception?

In response to the first question, proponents of Cognitive Intentionalism claim that the phenomenal properties of cognition are identical with intentional properties of cognition, whereas opponents claim that they are distinct. In response to the second question, proponents of Reductionism claim that the phenomenal properties of cognition are identical with phenomenal properties of sensory perception, whereas opponents claim that they are distinct and sui generis.

This article explores some of the broader philosophical issues that are at stake in these debates about the nature of cognitive phenomenology. The Reduction Question has fairly direct implications for theories of consciousness, since many theories of consciousness imply a form of Reductionism on which all consciousness is sensory or perceptual in nature. For instance, Tye (1995), Dretske (1995), and Carruthers (2000) endorse theories on which all conscious states are representational states that have nonconceptual or analogue content. If all such representational states are perceptual states, then it follows that all conscious states are perceptual states. More recently, Prinz (2012) has argued that all conscious states are intermediate-level perceptual states that are modulated by attention. If Reductionism is false, then these theories must be rejected or at least revised in order to account for both perceptual and non-perceptual forms of consciousness. 
The Reduction Question also bears indirectly on the Intentionality Question, since it is often supposed that if Reductionism is true, then Cognitive Intentionalism is false. As we saw in the previous article, proponents of Cognitive Intentionalism must respond by arguing either that Reductionism is false or that it can in fact be reconciled with Cognitive Intentionalism. In any case, this article will be primarily focused on philosophical implications of debates about Cognitive Intentionalism, while debates about Reductionism will remain largely in the background.

The Intentionality Question bears on a wide range of issues in philosophy of mind and epistemology, including not only the nature of the relationship between consciousness and intentionality, but also the epistemic role of consciousness in providing us with introspective knowledge of our own minds and knowledge of the external world. As we shall see, some philosophers appeal to specific claims about the nature of cognitive phenomenology in defending more general claims about the significance of phenomenal consciousness, while others appeal to general claims about the significance of phenomenal consciousness in arguing for more specific claims about the nature of cognitive phenomenology. Therefore, debates about the nature and significance of cognitive phenomenology are bound up with more general debates about the nature and significance of phenomenal consciousness.

My discussion of the significance of cognitive phenomenology is organized around three proposals about the significance of phenomenal consciousness:

(1) Phenomenal consciousness is the basis of intentionality.

(2) Phenomenal consciousness is the basis of introspective self-knowledge. 
(3) Phenomenal consciousness is the basis of knowledge of the external world.

The structure of the article is as follows: section two explores the relationship between intentionality and consciousness, while section three explores the role of consciousness in introspective self-knowledge, and section four explores its role in knowledge of the external world.

\section{Consciousness and Intentionality}

This section explores the implications of debates about the nature of cognitive phenomenology for the relationship between consciousness and intentionality, including the prospects for isolating the hard problem of explaining consciousness from the easy problem of explaining intentionality. ${ }^{1}$

Explaining consciousness is regarded as a hard problem because there is an explanatory gap between physical facts and phenomenal facts: it is conceivable that the same physical states could give rise to different conscious states or none at all. In the absence of an intelligible connection between consciousness and the physical world, it is hard to see how consciousness can be explained in terms of its physical basis alone. Explaining intentionality, by contrast, is often thought to be an easy problem on the grounds that there is no such explanatory gap between physical facts and intentional facts: it is inconceivable that the same physical facts could give rise to different intentional states or none at all. Thus, it is widely supposed that intentionality can be explained in terms of physical facts about the causal role of 
intentional states, including their causal relationships to other intentional states, their behavioral outputs, their environmental inputs, and so on. ${ }^{2}$

Until recently, the dominant view was that consciousness and intentionality are distinct and merely contingently related dimensions of the mind. On this view, the hard problem of explaining consciousness can be isolated from the easy problem of explaining intentionality. More recently, however, it has become more popular to claim that there is a necessary connection, and perhaps even an identity, between consciousness and intentionality. According to Intentionalism, for instance, all phenomenal properties are identical with and supervene upon intentional properties. On this view, the problem of explaining consciousness cannot be divorced from the problem of explaining intentionality.

As we saw in the previous article, there is a further question about whether Intentionalism should be restricted to perception or extended also to cognition. If it is restricted - that is, if Cognitive Intentionalism is false - then the problem of explaining the intentionality of cognition can be solved independently of the problem of explaining consciousness. But if it is extended - that is, if Cognitive Intentionalism is true - then these problems are inextricably intertwined.

If Intentionalism is true, then the prospects for explaining consciousness stand or fall with the prospects for explaining intentionality. Proponents of Intentionalism react to this situation in one of two ways. Those who adopt Reductive Intentionalism claim that the problem of explaining consciousness is made easier by its connection with the problem of explaining intentionality. ${ }^{3}$ On this view, we can explain consciousness by explaining intentionality in combination with further 
conditions that explain why some intentionality is conscious. Those who adopt NonReductive Intentionalism, on the other hand, maintain that the problem of explaining intentionality is no easier than the problem of explaining consciousness. ${ }^{4}$ On this view, the problem of explaining consciousness is not made easier by connecting it with the explanation of intentionality; on the contrary, this only makes the explanation of intentionality more difficult.

Intentionalism has further implications for the theory of intentionality aside from its impact on the hard problem of consciousness. For instance, Horgan and Graham (2012) argue that we cannot explain the intentionality of cognition without appealing to a version of Cognitive Intentionalism on which cognition has phenomenal intentionality - that is, it has a kind of intentionality that is identical with (or "wholly constituted by") phenomenal consciousness. Their argument can be reconstructed as follows:

(1) Cognition has determinate intentionality.

(2) Cognition has determinate intentionality only if some cognition has phenomenal intentionality.

(3) Therefore, some cognition has phenomenal intentionality.

The first premise of this argument is hard to deny, since it is an introspective datum that cognition has some degree of determinate intentionality. After all, we know the contents of our thoughts, judgments, and inferences by introspection and we know that their contents are not radically indeterminate. Meanwhile, the second premise 
is motivated by the observation that the intentionality of cognition is underdetermined by standard attempts to explain it in terms of its physical basis. ${ }^{5}$ Horgan and Graham argue that these indeterminacy problems arise because of a failure to appreciate the role that consciousness plays in grounding the determinate intentionality of cognition. Their proposal is that conscious cognition has determinate intentionality in virtue of its determinate phenomenal character, whereas unconscious cognition has determinate intentionality in virtue of its connection with the determinate intentionality of conscious cognition.

This proposal forms part of a larger project to establish that all intentionality has its source in phenomenal consciousness. ${ }^{6}$ According to Horgan and Graham, consciousness is an "anchor point" for intentionality in the sense that all unconscious intentional states are integrated within a network that includes conscious intentional states. This view is motivated, as before, by the claim that the determinacy of conscious intentionality derives from its phenomenal character, whereas the determinacy of unconscious intentionality derives from its connections with conscious intentionality. Hence, the argument can be generalized as follows:

(1) Intentionality has determinate intentional properties.

(2) Intentionality has determinate intentional properties only if some intentionality is phenomenal intentionality.

(3) So, some intentionality is phenomenal intentionality. 
In the previous article, we saw that there are good reasons to deny that all intentionality is phenomenal intentionality, since there are unconscious intentional states that play an indispensable role in commonsense explanations of action and computational explanations in cognitive science. Horgan and Graham do not claim that all intentionality is phenomenal intentionality, but they do make the weaker claim that all intentionality has its source in phenomenal intentionality. So, they can allow for the existence of unconscious intentional states, but only insofar as they stand in the right kind of relations to conscious intentional states.

However, even this weaker claim is too strong. Cognitive science provides good reason to believe in the existence of unconscious intentional states that do not stand in any interesting relationship to conscious intentional states. For instance, Milner and Goodale (1995) argue that there are unconscious visual representations that play a role in fine-tuning the spatial parameters of visually guided actions, although they do not play any role in the visual processing that yields conscious visual experience. It may be objected that there are functional connections between the visual processing that underpins conscious visual experience and the unconscious control of action, but these connections are highly circumscribed. Moreover, as Burge (2010) suggests, there is good reason to suppose that there are unconscious visual representations of this kind in primitive creatures that have no conscious visual experience at all, such as honey bees and desert ants. ${ }^{7}$

Horgan and Graham's argument is undermined by the empirical evidence against their claim that all intentionality has its source in consciousness. Nevertheless, there may be important theoretical distinctions to be drawn between 
intentionality that has its source in consciousness and intentionality that has its source elsewhere. So, even if we abandon the hypothesis that consciousness is the basis of all intentionality, we need not abandon the search for an alternative hypothesis about the significance of consciousness. One such hypothesis is that the significance of consciousness consists in its epistemic role as a source of introspective self-knowledge and knowledge of the external world. In the sections to follow, I consider arguments about the nature of cognitive phenomenology that appeal to this claim about the epistemic role of consciousness.

\section{Consciousness and Introspection}

This section explores the implications of debates about the nature of cognitive phenomenology for theories of introspection. The starting point for any theory of introspection is that there is an epistemic asymmetry between first-person and third-person perspectives such that each of us has a distinctive way of knowing about own minds that is not available to anyone else. The term 'introspection' can be used as a placeholder for this distinctive way of knowing our own minds, although different theories of introspection provide different accounts of its nature. For current purposes, I will assume only that introspection is distinct from other ways of knowing about the world that rely on inference and sensory perception. ${ }^{8}$

We all have introspective knowledge of our own conscious experience. For instance, I know by introspection whether I am feeling pain or pleasure and whether I am visually experiencing red or green. Moreover, it seems plausible that the phenomenal character of my experience explains how I know these things. There is 
a phenomenal difference between feeling pain and pleasure and, similarly, between visually experiencing red and green. Intuitively, it is because of these phenomenal differences that I can know by introspection whether I feel pain or pleasure and whether I am visually experiencing red or green.

This line of reasoning seems to generalize from perception to cognition. For instance, I know by introspection whether I am thinking about apples or oranges, politics or religion. And, as before, it seems plausible that the phenomenal character of my experience explains how I know these things. Intuitively, it is because there is a phenomenal difference between thinking about apples and oranges, or politics and religion, that I can know by introspection which of these thoughts I am thinking. In each case, the datum to be explained is that we have introspective knowledge of the intentional properties of conscious experience. Moreover, in each case, this datum seems best explained by Intentionalism, according to which conscious experience has a kind of intentionality - namely, phenomenal intentionality - that is identical with phenomenal consciousness. If Intentionalism is true, then the phenomenal properties of experience are identical with intentional properties, and so introspective knowledge of the phenomenal properties of experience provides us with introspective knowledge of its intentional properties.

David Pitt (2004; see also Goldman 1993) argues on similar grounds that we cannot explain our introspective knowledge of which thoughts we are thinking except by appealing to what he calls the "proprietary, distinctive, and individuative" phenomenology of thought. According to Pitt, the phenomenal character of entertaining a proposition is proprietary in the sense that it is different from the 
phenomenal character of adopting any other attitude to the same proposition, distinctive in the sense that it is different from the phenomenal character of adopting the same attitude towards any other proposition, and individuative in the sense that its phenomenal character is identical with its intentional content. Thus, Pitt argues for a form of Cognitive Intentionalism on which the phenomenal properties of cognition are identical with intentional properties and so cognition has phenomenal intentionality.

Pitt's argument can be reconstructed and generalized as follows:

(1) We have introspective knowledge of intentional properties of cognition.

(2) We have introspective knowledge of intentional properties of cognition only if some cognition has phenomenal intentionality.

(3) Therefore, some cognition has phenomenal intentionality.

Opponents of Cognitive Intentionalism must either deny premise one by arguing that we do not have introspective knowledge of the intentional properties of cognition or deny premise two by arguing that introspective knowledge of the intentional properties of cognition can be explained without appealing to Cognitive Intentionalism. Let us consider each of these strategies in turn.

An extreme version of the first strategy would be to deny that we have any introspective knowledge at all. Thus, Ryle (1949) notoriously claimed that we know our own minds in the same way that we know the minds of others - that is, by inference from observation of physical behavior. The problem with Ryle's proposal 
is that it cannot explain how we know what we're thinking in cases where thought exerts no causal influence on behavior. A less radical alternative would be to claim, as Carruthers (2011) does, that we have introspective knowledge of intentional properties of perception, but not cognition. ${ }^{9}$ On this proposal, knowledge of intentional properties of cognition depends on inference from introspective knowledge of perceptual experience as well as perceptual knowledge of physical behavior. But this proposal, like Ryle's, faces problems explaining how we know what we're thinking in certain cases - namely, cases in which our thoughts are causally insulated from perceptual experience as well as physical behavior. ${ }^{10}$

The second strategy, unlike the first, concedes that we have introspective knowledge of intentional properties of cognition, but maintains that this can be explained without appealing to the claim that cognition has distinctively phenomenal intentionality. Typically, proponents of this strategy argue that our introspective knowledge of cognition can be explained in terms of the operation of a reliable introspective mechanism. For instance, Nichols and Stich (2003: Ch. 4) argue that our knowledge of belief can be explained by a "monitoring mechanism" that takes as input a representation that $p$ in the "belief box" and yields as output a representation that I believe that $p$ in the belief box by means of a non-inferential process. Similarly, our knowledge of what we're thinking can be explained by a mechanism that takes as input a representation that $p$ in the "thinking box" and yields as output a representation that I am thinking that $p$ in the belief box. The claim is that such a mechanism generates introspective knowledge even if the representations that it takes as input lack phenomenal intentionality. 
A number of objections to this account have been proposed in the literature. Pitt's (2004) objection is that it fails to explain the distinctive character of our introspective knowledge of cognition. Pitt claims that introspective knowledge of conscious thought is analogous to perceptual knowledge of objects insofar as it is a kind of knowledge by acquaintance - that is, knowledge that is made available by conscious acquaintance that phenomenally presents its object as being some way. However, this objection relies on a controversial claim about the nature of introspection - namely, that introspective knowledge of our own minds should be explained on the same model as perceptual knowledge of the external world. Moreover, perceptual acquaintance with an object does not require the object in question to be conscious, which raises the question why introspective acquaintance with cognition requires one's cognition to be conscious. ${ }^{11}$

Goldman's $(1993,2006)$ objection is that this account fails to explain our introspective knowledge of the attitudes, since our introspective mechanisms cannot determine whether a representation plays the functional role of belief or desire - that is, whether it is located in the "belief box" or the "desire box". Here, Goldman relies on an analogy with perception: we cannot see that a coin is a dime just by looking; rather, we see its intrinsic properties and we infer that anything with those intrinsic properties is a dime. Similarly, we cannot know by introspection whether a representation plays such-and-such functional role; rather, we introspect its intrinsic properties and we infer that anything with those intrinsic properties plays such-and-such functional role. ${ }^{12}$ However, Goldman's objection, like Pitt's, 
relies upon a controversial assumption about the nature of introspection - namely, that it should be explained on the model of perception.

A better objection, in my view, is that this account relies upon an implausible form of reliabilist epistemology: the reliability of a belief-forming mechanism is not sufficient to explain justified belief or knowledge. Following BonJour (1985), we can imagine a reliable clairvoyant mechanism that is activated by the movements of the President of the United States and yields beliefs about his current location. The existence of such a mechanism is not sufficient to yield knowledge or justified belief about the current location of the President. But if the reliability of a belief-forming mechanism is not sufficient to explain knowledge about the external world, then why suppose that the reliability of an introspective mechanism is sufficient to explain introspective knowledge of one's own mind?

To illustrate the point further, consider Ned Block's (1995) example of the "super-blindsighter", who lacks conscious perceptual experience of objects in his blind field, but forms reliably true beliefs about these objects on the basis of unconscious perceptual representations. The mere fact that his beliefs are formed on the basis of a reliable mechanism does not make them justified. And similar remarks apply to the "hyper-blindsighter", who forms reliably true beliefs about his unconscious visual representations on the basis of a reliable introspective mechanism. Again, the mere fact that such beliefs are formed on the basis of a reliable mechanism does not make them justified. In each case, the absence of conscious experience explains why the beliefs in question are not justified. And so, it 
seems, we cannot avoid the appeal to phenomenal consciousness in explaining our introspective knowledge of cognition. ${ }^{13}$

There are residual challenges for the proposal that introspective knowledge of cognition is explained in terms of its phenomenal character. Most obviously, we have introspective knowledge of what we believe, but we cannot explain this by appealing to the phenomenal character of belief, since beliefs are not phenomenally conscious states. One option, of course, is to reject the assumption that we have introspective knowledge of what we believe, but this is no more plausible for belief than it is for occurrent thought and judgment. A better option is to explain our introspective knowledge of belief in a way that makes it depend upon the phenomenal character of its conscious manifestations in judgment. ${ }^{14}$

Another challenge stems from the assumption that we have introspective knowledge of intentional properties that are externally individuated by their relations to the environment as well as intentional properties that are individuated by their phenomenal character. For instance, I know by introspection that I think that water is wet, but the intentional properties of my water-thoughts depend not only on their phenomenal character, but also on the chemical composition of the watery stuff in my environment. One option here is to deny that cognition has externally individuated intentional properties or to deny that we know them by introspection. ${ }^{15}$ But perhaps a more promising strategy is to argue that our introspective knowledge of the externally individuated properties of cognition can be explained in a way that depends upon our introspective knowledge of the phenomenal properties of cognition. The issue deserves further discussion. ${ }^{16}$ 
A final challenge is to explain the connection between phenomenal consciousness and introspective knowledge. Some explain the connection by appealing to the nature of phenomenal consciousness, while others explain it by appealing to the nature of introspective knowledge. On views of the first kind, the nature of phenomenal consciousness is such that it provides a source of introspective knowledge. For instance, Horgan and Kriegel (2007) argue that phenomenal consciousness is self-presenting in the sense that phenomenally conscious states essentially represent themselves. One's introspective knowledge of conscious experience is explained as a matter of forming beliefs on the basis of representations of those experiences that are essentially built into the experiences themselves. On views of the second kind, the nature of introspective knowledge is such that it has its source in phenomenal consciousness. For instance, Smithies (2012a) argues for a simple theory of introspection, according to which one has an introspective way of knowing that one is in a certain phenomenally conscious or phenomenally individuated mental state just by virtue of being in that mental state. The nature of the relationship between introspection and phenomenal consciousness remains an important topic for future research. ${ }^{17}$

\section{Consciousness and Epistemology}

This section explores further implications of debates about the nature of cognitive phenomenology for our understanding of the epistemic role of consciousness. We can distinguish two aspects of the epistemic role of consciousness: in addition to providing us with introspective knowledge of our own minds, it also provides us 
with knowledge and justified belief about the external world. In this section, we will focus on this second aspect of its epistemic role.

The epistemic role of consciousness in justifying beliefs about the external world is most apparent in the case of perception. Two points are relevant here. First, if one has a perceptual experience in which it seems to one that $p$, then one has at least defeasible justification to believe that $p$. And second, it is in virtue of the phenomenal character of its perceptually seeming to one that $p$ that one has defeasible justification to believe that $p .{ }^{18}$ To illustrate these points, consider that a subject with blindsight (or "super-blindsight") who has an unconscious perceptual representation that $p$ without the distinctive phenomenal character of its seeming that $p$ does not thereby have even defeasible justification to believe that $p$.

Debates about the nature of cognitive phenomenology are vital for deciding how widely the epistemic role of consciousness extends. If Reductionism is false, then we face questions about the epistemic role of non-perceptual consciousness. And if Intentionalism can be extended from perception to cognition, then we face questions about whether perceptual experience and cognitive experience are similar enough to play the same kind of epistemic role.

A number of philosophers have recently argued that the epistemic role of cognitive experience is structurally parallel to that of perceptual experience. ${ }^{19}$ Thus, it has been argued that if one has a cognitive experience in which it seems to one that $p$, then one has at least defeasible justification to believe that $p$; and moreover, it is in virtue of the phenomenal character of its cognitively seeming to one that $p$ that one has defeasible justification to believe that $p$. According to Huemer (2001), 
we can subsume the epistemic roles of perceptual and cognitive experience under a more general principle of Phenomenal Conservatism:

Phenomenal Conservatism: if one has a phenomenal experience in which it seems to one that $p$, then one has defeasible justification to believe that $p$ in virtue of the phenomenal character of its seeming to one that $p .{ }^{20}$

The distinction between a priori and a posteriori justification can now be explained as follows: a priori justification has its source in cognitive experience, whereas a posteriori justification has its source in perceptual experience. Thus, BonJour (1998) argues that we cannot explain the existence of a priori knowledge without appealing to the distinctive phenomenal character of cognitive experience.

Is it plausible to suppose that perceptual and cognitive experiences play the same kind of epistemic role? Perceptual experiences are often thought to be foundational in the sense that they justify beliefs without standing in need of justification themselves. In BonJour's (1985: 30) terminology, perceptual experiences are "epistemological unmoved movers". Moreover, it is often thought that perceptual experiences are suited to play this foundational epistemic role only if they are distinct from the beliefs they justify. After all, beliefs do not justify other beliefs unless they are justified themselves. This prompts the question whether cognitive experiences, like perceptual experiences, are distinct from beliefs.

In this connection, it will be useful to draw a distinction between doxastic and non-doxastic theories of cognitive experience. According to doxastic theories, 
cognitive experiences are doxastic states, such as conscious judgments or conscious dispositions towards judgment. ${ }^{21}$ If such theories are correct, then it not clear that cognitive experiences can play a foundational epistemic role in the same way as perceptual experiences. After all, it seems plausible that doxastic states, including judgments and conscious inclinations towards judgment, can provide justification for other doxastic states only if they are justified themselves. According to nondoxastic theories, by contrast, cognitive experiences are non-doxastic states that cause and justify doxastic states such as conscious judgments and conscious dispositions towards judgment. ${ }^{22}$ If such theories are correct, then cognitive experiences, like perceptual experiences, may be more suited to play a foundational epistemic role. On the other hand, it is not clear that we have non-doxastic cognitive experiences of the right kind to play this epistemic role.

Consider Goldman's (1999) "problem of forgotten evidence”. We form many of our beliefs, including beliefs about geography and history, on the basis of evidence that is subsequently forgotten, although the beliefs themselves are retained. Moreover, it seems that we are justified in retaining many of these beliefs without remembering the evidence on which they were originally based. The problem is to explain what makes those beliefs justified. For instance, what justifies my belief that Henry the Eighth had six wives? Proponents of Phenomenal Conservatism might say that, when I consider the question, I have a cognitive experience in which it seems to me that Henry the Eighth had six wives. ${ }^{23}$ However, there are two problems with this answer. First, my belief is already justified before I 
have this cognitive experience. And second, this cognitive experience is plausibly nothing but the conscious manifestation of my belief.

In my view, a better solution to the problem of forgotten evidence is to reject the assumption that beliefs and other doxastic states cannot play a foundational epistemic role. It is true that beliefs justify other beliefs only if they are justified themselves, whereas perceptual experiences can justify beliefs without standing in need of any justification. But not all beliefs are justified by other beliefs, since some beliefs are justified by default. As an alternative to Phenomenal Conservatism, consider the following principle of Doxastic Conservatism:

Doxastic Conservatism: if one believes that $\mathrm{p}$, then one thereby has defeasible justification to believe that $p .^{24}$

According to Doxastic Conservatism, if I believe that Henry the Eighth had six wives, I have default justification to retain my belief regardless of how it was originally formed. Since this justification is defeasible, it can be defeated - for instance, by evidence that my belief was originally formed in an unreliable way. In the absence of defeaters, however, I am default justified in retaining my belief despite having forgotten the evidence on which it was originally formed.

Davidson (1986) claimed that nothing can justify a belief except another belief. This is surely an over-reaction, since beliefs can be justified by perceptual experiences, which are distinct from the beliefs they justify. And yet it would be an over-reaction in the opposite direction to claim that beliefs can never be justified by 
other beliefs. If belief plays an epistemic role, however, then we may need to rethink our understanding of the epistemic role of consciousness.

Some proponents of Phenomenal Conservatism endorse a strengthened version of the principle on which phenomenal seemings are both necessary and sufficient for justification in something like the following way:

Strong Phenomenal Conservatism: one has justification to believe that $p$ if and only if one has defeasible justification to believe that $p$ in virtue of having a phenomenal experience in which it seems to one that $p$ and, moreover, one's defeasible justification is not defeated by any conflicting seemings. ${ }^{25}$

On this view, which propositions one has justification to believe at any given time depends solely upon which propositions seem true to one at that time. Thus, Strong Phenomenal Conservatism implies Strong Phenomenal Mentalism:

Strong Phenomenal Mentalism: Which propositions one has justification to believe at any given time depends solely on one's phenomenally conscious mental states at that time.

If Doxastic Conservatism is true, on the other hand, then which propositions one has justification to believe at any given time depends not only on one's phenomenally conscious experiences at that time, but also on one's standing beliefs. If two subjects have the same phenomenally conscious experiences, but differ in their standing 
beliefs, then they may differ in which propositions they have justification to believe. Doxastic Conservatism therefore generates counterexamples to Strong Phenomenal Mentalism.

How should we reformulate the epistemic role of consciousness in order to accommodate the epistemic role of belief? Smithies (2012a, forthcoming) proposes the following:

Weak Phenomenal Mentalism: Which propositions one has justification to believe at any given time depends solely upon one's phenomenally individuated mental states at that time.

The proposal is that although one's beliefs are not phenomenally conscious states, they are phenomenally individuated in a derivative way by their dispositions to cause phenomenally conscious states of judgment. On this view, phenomenally conscious judgments are individuated by their phenomenal character, whereas standing beliefs are individuated by their dispositions to cause the phenomenal character of phenomenally conscious judgment. Moreover, the main argument for this proposal is that we can explain why beliefs and judgments play an epistemic role by appealing to the claim that they are phenomenally individuated in this way, whereas "subdoxastic" states (such as tacit knowledge of syntax) do not play an epistemic role because they are individuated by their role in unconscious psychological processes. 
In summary, we can contrast two different accounts of the epistemic significance of cognitive experience. On one account, cognitive experience plays a foundational epistemic role that is structurally parallel to that of perceptual experience: it provides justification for belief without needing any justification in its turn. On a contrasting account, beliefs play a foundational epistemic role that is different from the role of perceptual experience: they provide justification for other beliefs only if they are justified themselves. Nevertheless, beliefs are suited to play this epistemic role only insofar as they are disposed to cause cognitive experiences of judgment. No doubt other accounts can be given too. The connections between the nature of cognitive phenomenology and the epistemic role of consciousness remain important topics for future research.

\section{Conclusions}

The aim of this article was to explain how debates about the nature of cognitive phenomenology are bound up with larger debates about the significance of phenomenal consciousness. In order to make progress in debates about the nature of cognitive phenomenology, we cannot rely on introspection alone. Instead, we must integrate these debates with our theoretical reflections on the connections between consciousness, intentionality, and epistemology. 


\section{References}

Bealer, G. 'A Theory of the A Priori.' Pacific Philosophical Quarterly 81.1 (2000): 1-30.

Bengson, J. The Intellectual Given. Ph.D. Dissertation. University of Texas at Austin, 2010.

Boghossian, P. 'Content and Self-Knowledge.' Philosophical Topics 17.1 (1989): 5-26.

BonJour, L. The Structure of Empirical Knowledge. Cambridge, MA: Harvard UP, 1985.

----. In Defense of Pure Reason. Cambridge: Cambridge UP, 1998.

Burge, T. Origins of Objectivity. New York, NY: Oxford UP, 2010.

Carruthers, P. Phenomenal Consciousness: A Naturalistic Theory. Cambridge: Cambridge UP, 2000.

----. The Opacity of Mind: An Integrative Theory of Self-Knowledge. New York, NY: Oxford UP, 2011.

Chalmers, D. 'Facing Up to the Problem of Consciousness.' Journal of Consciousness Studies 2.3 (1995): 200-219.

----. 'The Representational Character of Experience.' Ed. B. Leiter, The Future for Philosophy. New York, NY: Oxford University Press, 2004.

Chudnoff, E. 'The Nature of Intuitive Justification.' Philosophical Studies 153.2 (2011a): 313-33.

----. 'What Intuitions are Like.' Philosophy and Phenomenological Research 82.3 (2011b): 625-54.

Conee, E. and R. Feldman. 'Internalism Defended.' American Philosophical Quarterly 38.1 (2001): 1-18. 
Davidson, D. 'Radical Interpretation.' Dialectica 27 (1973): 313-28.

----. 'A Coherence Theory of Truth and Knowledge.' Ed. E. LePore, Truth and Interpretation: Perspectives on the Philosophy of Donald Davidson. Oxford: Blackwell, 1986.

Dretske, F. Naturalizing the Mind. Cambridge, MA: MIT Press, 1995.

Farkas, K. 'Phenomenal Intentionality without Compromise.' The Monist 91.2 (2008): 273-93.

Goldman, A. 'The Psychology of Folk Psychology.' Behavioral and Brain Sciences 16 (1993): 15-28.

----. 'Internalism Exposed.' The Journal of Philosophy 96 (1999): 271-93.

----. Simulating Minds: The Philosophy, Psychology and Neuroscience of Mindreading. New York, NY: Oxford UP, 2006.

Gopnik, A. 'How We Read Our Own Minds: The Illusion of First-Person Knowledge of Intentionality.' Behavioral and Brain Sciences 16 (1993): 1-14.

Harman, G. Change in View: Principles of Reasoning. Cambridge, MA: MIT Press, 1986.

Horgan, T. and G. Graham. 'Phenomenal Intentionality and Content Determinacy.' Ed. R. Schantz, Prospects for Meaning. Berlin: De Gruyter, 2012.

Horgan, T. and U. Kriegel. 'Phenomenal Epistemology: What is Consciousness That We May Know It So Well?' Philosophical Issues 17 (2007): 123-144.

Horgan, T. and J. Tienson. 'The Intentionality of Phenomenology and the Phenomenology of Intentionality.' Ed. D. Chalmers, Philosophy of Mind: Classical and Contemporary Readings, New York, NY: Oxford UP, 2002. 
Huemer, M. Skepticism and the Veil of Perception. Lanham, MD: Rowman and Littlefield, 2001.

----. 'Compassionate Phenomenal Conservatism.' Philosophy and Phenomenological Research 74.1 (2007): 30-55.

Koksvik, O. Intuition. Ph.D. Dissertation. Australian National University, 2011.

Kriegel, U. The Sources of Intentionality. New York, NY: Oxford UP, 2011.

Kripke, S. Wittgenstein on Rules and Private Language. Cambridge, MA: Harvard UP, 1982.

Levine, J. 'Materialism and Qualia: the Explanatory Gap.' Pacific Philosophical Quarterly 64 (1983): 354-61.

Loar, B. 'Phenomenal Intentionality as the Basis of Mental Content.' Ed. M. Hahn and B. Ramberg, Reflections and Replies: Essays on the Philosophy of Tyler Burge, Cambridge MA: MIT Press, 2003.

Loewer, B. 'A Guide to Naturalizing Semantics.' Ed. B. Hale and C. Wright, A Companion to the Philosophy of Language, Oxford: Blackwell, 1997.

Ludlow, P. and N. Martin. Externalism and Self-Knowledge. Stanford, CA: CSLI, 1998.

Lycan, W. Consciousness and Experience. Cambridge MA: MIT Press, 1996.

McGinn, C. 'Consciousness and Content.' Proceedings of the British Academy 74 (1988): 219-39.

McGrath, M. 'Memory and Epistemic Conservatism.' Synthese 157 (2005): 1-24.

Milner, D. and M. Goodale. The Visual Brain in Action, New York, NY: Oxford University Press, 1995.

Nagel, T. 'What is it Like to be a Bat?' The Philosophical Review 83.4 (1974): 435-50. 
Nichols, S. and S. Stich. Mindreading: An Integrated Account of Pretence, SelfAwareness, and Understanding Other Minds. New York, NY: Oxford UP, 2003.

Peacocke, C. 'Conscious Attitudes, Attention and Self-Knowledge.' Eds. C. Wright, B. Smith and C. MacDonald, Knowing Our Own Minds, Oxford: Clarendon Press, 1998.

Pitt, D. 'The Phenomenology of Cognition, Or, What is it Like to Think that P?' Philosophy and Phenomenological Research 69 (2004): 1-36.

Prinz, J. 'All Consciousness is Perceptual.' Ed. B. McLaughlin and J. Cohen, Contemporary Debates in Philosophy of Mind. Oxford: Blackwell, 2007.

----. The Conscious Brain: How Attention Engenders Experience. New York, NY: Oxford UP, 2012.

Pryor, J. 'The Skeptic and the Dogmatist.' Nous 34 (2000): 517-549.

----. 'What's Wrong with Moore's Argument?' Philosophical Issues 14 (2004): 34978.

Putnam, H. Reason, Truth and History. Cambridge: Cambridge UP, 1981.

Quine, W. V. O. Word and Object. Cambridge, MA: MIT Press, 1960.

Ryle, G. The Concept of Mind. Chicago, IL: Chicago UP, 1949.

Searle, J. 'Consciousness, Explanatory Inversion and Cognitive Science.' Behavioral and Brain Sciences 13 (1990): 585-96.

Siewert, C. The Significance of Consciousness, Princeton, NJ: Princeton UP, 1998.

Silins, N. 'Judgment as a Guide to Belief.' Ed. D. Smithies and D. Stoljar, Introspection and Consciousness. New York, NY: Oxford University Press, 2012. 
Smithies, D. 'What is the Role of Consciousness in Demonstrative Thought?' The Journal of Philosophy 108.1 (2011): 5-34.

----. 'A Simple Theory of Introspection.' Ed. D. Smithies and D. Stoljar, Introspection and Consciousness. New York, NY: Oxford University Press, 2012a.

----. 'The Mental Lives of Zombies.' Philosophical Perspectives 26 (2012b): 343-72.

----. 'The Phenomenal Basis of Epistemic Justification.' Ed. J. Kallestrup and M. Sprevak, New Waves in Philosophy of Mind. Palgrave Macmillan, forthcoming. Smithies, D and D. Stoljar. Introspection and Consciousness. New York, NY: Oxford University Press, 2012.

Sosa, E. 'Minimal Intuition.' Ed. M. DePaul and W. Ramsey, Rethinking Intuition: The Psychology of Intuition and Its Role in Philosophical Inquiry. Rowman and Littlefield, 1998.

Stich, S. and T. Warfield. Mental Representation: A Reader. Oxford, Blackwell, 1994.

Strawson, G. Mental Reality. Cambridge, MA: MIT Press, 1994.

----. 'Real Intentionality.' Phenomenology and the Cognitive Sciences 3 (2004): 287313.

Tye, M. Ten Problems of Consciousness, Cambridge, MA: MIT Press, 1995.

Williamson, T. The Philosophy of Philosophy. Oxford, Blackwell, 2007.

\footnotetext{
${ }^{1}$ See Chalmers (1995) for the distinction between hard and easy problems of consciousness. See also Nagel (1974) and Levine (1983) for influential discussion of the explanatory gap.

${ }^{2}$ See the introduction and essays in Stich and Warfield (1994) for a range of strategies for explaining intentionality in terms of its physical basis.

3 Proponents of Reductive Intentionalism include Dretske (1995), Tye (1995) and Lycan (1996).
} 
4 Proponents of Non-Reductive Intentionalism include McGinn (1988), Siewert (1998), Horgan and Tienson (2002), Loar (2003) and Chalmers (2004).

5 See Quine (1960), Davidson (1973), Putnam (1981) and Kripke (1982) for classic discussions of the problem of radical interdeterminacy. See also Loewer (1997) for discussion of underdetermination problems in connection with recent attempts to explain intentionality in physical terms.

${ }^{6}$ See also Searle (1990), Strawson $(1994,2004)$ and Kriegel (2011) for variations on this project.

${ }^{7}$ See Smithies (2012b) for further discussion of this objection.

${ }^{8}$ See Smithies and Stoljar (2012) for a survey of theories of introspection.

9 See also Gopnik (1993) for a related view on which we have introspective knowledge of phenomenal consciousness ("the Cartesian buzz") but not intentionality.

${ }^{10}$ See Goldman (2006: Ch.9) for a similar objection. See also the discussion of Carruthers' response to Hurlburt's empirical research on "noniconic thinking" in the previous article.

${ }^{11}$ See the chapters in Bayne and Montague (2011) by Levine, Pitt, and Tye and Wright for discussion of these criticisms of Pitt's argument.

12 Compare Boghossian (1989) for a related line of argument. Goldman (1993) argues that phenomenal properties are the only intrinsic properties to which our introspective mechanisms are sensitive, whereas Goldman (2006: Ch.9) allows that our introspective mechanisms are sensitive also to neural properties, so he now also rejects the second premise of Pitt's argument.

${ }^{13}$ See Smithies $(2011,2012 a)$ for more detailed discussion of super-blindsight and hyper-blindsight in the context of the epistemic role of consciousness in perceptual and introspective knowledge.

${ }^{14}$ See Peacocke (1998), Silins (2012), and Smithies (2012a) for contrasting attempts to explain our introspective knowledge of belief by appeal to the phenomenal character of occurrent judgment.

${ }^{15}$ Farkas (2008) denies that cognition has externally individuated intentional properties.

16 See the essays in Ludlow and Martin (1998) for discussion of the compatibility between externalism and self-knowledge. See also Horgan and Tienson (2002) for discussion of the relationship between phenomenal intentionality and externally individuated intentionality. 
17 See the essays in Smithies and Stoljar (2012) for a range of perspectives on the relationship between introspection and phenomenal consciousness.

18 Pryor (2000) argues for a version of dogmatism, according to which if one has a perceptual experience which basically represents that $p$, then one has immediate, defeasible justification to believe that $p$. Pryor $(2000: 547$ n. 37; 2004: 357) also appeals to the phenomenology of perceptual experience in explaining why it plays this epistemic role.

${ }^{19}$ See BonJour (1998), Bealer (2000), Huemer (2001), Chudnoff (2011a; 2011b), Bengson (2010) and Koksvik (2011) for proposals of this kind.

${ }^{20}$ Compare Huemer's (2001: 99) Principle of Phenomenal Conservatism: "If it seems to S that $p$, then S thereby has at least prima facie justification for believing that $p . "$

${ }^{21}$ See Sosa (1998) and Williamson (2007) for versions of this proposal.

22 Thus, Bealer (2000: 4) writes, "My view is simply that, like sensory seeming, intellectual seeming (intuition) is just one more primitive propositional attitude." Chudnoff (2011a; 2011b) argues that perceptual and intuitive seemings have presentational phenomenology in virtue of which they provide justification for belief; compare Bengson (2010) and Koksvik (2011) for related proposals.

${ }^{23}$ Huemer (2001) appeals to "memory-related seemings". Similarly, Conee and Feldman (2001: 9) appeal to "conscious qualities of the recollection, such as its vivacity and...associated feeling of confidence."

${ }^{24}$ This view is also sometimes known as 'epistemic conservatism'. See Harman (1986) for a classic discussion and McGrath (2005) for a more recent discussion.

${ }^{25}$ Huemer (2007) seems to express sympathy for this strong principle of phenomenal conservatism. 